\title{
A Study on Detection of Adulteration in Milk Samples from Different Regions of Thuraiyur District in Tamil Nadu, India
}

\author{
N. Brindha", P. Chitra, R. Janarthanan and A. Murali \\ Department of Veterinary and Animal science, Tamil Nadu Agricultural University, \\ Coimbatore, Tamil Nadu, India \\ *Corresponding author
}

\section{A B S T R A C T}

Milk has been recognized as an almost complete food for man and it act as a source of essential nutrients like carbohydrate, protein, fat, vitamins and minerals. Milk is required for promoting growth and maintenance of health. It can however also serve as a vehicle for the transmission of chemicals and other impurities. The study was carried out keeping view on adulteration of milk with various additives to increase its marketability. This study

Keywords

Adulteration, Milk sample, Hygienic quality milk.

Article Info

Accepted:

26 October 2017

Available Online:

10 December 2017 explain in detail about the hygienic status of cooperative societies, local vendor and private sector packed milk, samples are collected in and around Thuraiyur district of Tamil Nadu, India and tested for determination of adulteration. Qualitative analyses were carried out on 30 samples collected from this three sectors analyzed by using standard adulterant kit purchased from private dealer, Thuraiyur, Tamil Nadu, India. Following are the significant observations of the study reveals cooperative societies show neutralizer $13 \%$, Sodium chloride 16\%, Acidity and Heat stability 23\%, Mastitis 20\%; Local vendor show neutralizer $10 \%$, sodium chloride $13 \%$, Acidity and Heat stability $40 \%$ and Mastitis $23 \%$; private sector milk shows only $3 \%$ for Sodium chloride. All percentage values are shows presence of adulterant. Due to rules laid by FSSAI, most of branded milk company follows standards for producing hygienic and good quality of milk. The finding of this study highlight's that majority of milk samples were adulterated with commonly using adulterants and preservatives which has both economic and public health importance. Hence, there is urgent need for creating awareness among the consumers and local milk vendors and cooperative societies about unethical malpractices in milk supplying chain which may cause health hazards to consumers.

\section{Introduction}

Milk is an important source of nutrient required for growth in infants and children and for maintenance of health in adults. Milk is a perfect food, readily digested and absorbed. It is a sole natural food for infants and children. But these days it is being adulterated with harmful substances which enhance its quantity and characteristics but reduces its quality. Adulterants are mainly added to increase the shelf life of milk. Next to egg, milk has high biological value. Adulteration in milk is considered to reduce the quality and to increase the quantity of milk. Adulterants are mainly added to increase the shelf life of milk. When consumers buy milk they have the right to assume that it will be pure and unadulterated. But, unfortunately, this is not always the case. 
It is sad to note that most Indians are resigned to drinking milk diluted with water which not only reduces the nutritious value of the beverage but also poses risk to health.

Normally, the adulteration in food is done either for financial gain or lack of proper hygienic conditions of processing, storing, transportation and marketing. This ultimately leads to the stage that the consumer is either cheated or becomes victim of diseases. Such types of adulteration are quite common in developing countries. It is equally important for the consumer to know the common adulterants and their effects on health. Milk is produced throughout the year. However, milk production is greatly reduced during summer months due to heat stress and scarcity of fodder. Milk is transported from point of production to cities mainly through middlemen. Such milk is watered/ skimmed to increase profit. To maintain its composition, materials like starch, flour, urea, cane sugar and vegetable oil are added as adulterants. Milk dealers may either dilute the milk or extract valuable components and there after add cheap substances to maintain its compositional parameters. These substances include starch, urea, preservatives like formalin, hydrogen peroxide, boric acid and various antibiotics. Urea is added for whitening of milk and only few grams of urea are enough to bring milk in its original state. Hydrogen peroxide is used as preservative usually in summer season when environmental temperature is very high. This unethical activity is usually adapted to prevent the financial losses due to the spoilage of milk during its transportation and sale. According to Basic Animal husbandry Statistics (2015-16) stated that the milk production for 2015-16 is 155.3 million tonnes. A national survey in India has revealed that almost $70 \%$ of the milk sold and consumed in India is adulterated by contaminants such as detergent and skim milk powder, but impure water is the highest contaminant.

According to National Survey on Milk Adulteration conducted by FSSAI (India) in 2011, water is the most common adulterant followed by detergent in milk. Of these 16.7 $\%$ were packet or branded milk and rest were loose milk samples from dairies. In the urban areas, $68.9 \%$ milk was found to be adulterated with water, detergent, urea and skim milk powder. In India, $88 \%$ milk was found to be adulterated.

\section{Materials and Methods}

\section{Survey method}

The local milk vendors, cooperative societies, packed milk from private sector were chosen via random sampling method. 30 samples from these three sectors were collected in a sterilized container and subjected to laboratory techniques to determine the adulterants present in milk sample.

\section{Study design}

Random sampling Design.

\section{Sample size}

30 unpasteurized milk samples were collected from 3 different sectors (Milk vendor, Cooperative societies and packet milk from private sector) located in and around Thuraiyur district, Tamil Nadu. Samples were kept in a sterilized container and stored in a refrigerator, later which were analyzed for adulteration properties which includes water, urea, starch, detergent test etc.,

\section{Test}

MAT (Milk Adulteration Testing kit) consisting of reagent bottles for qualitative 
detection of individual adulterants were purchased from private company and was used for determining the extent of adulterants like urea, starch, neutralizer, detergent, sugar, glucose-dextrose, sodium chloride, acidity and heat stability, hydrogen peroxide, mastitis, formalin, maltodextrin, nitratenitrogen.

\section{Detection of common adulterants}

Small adulteration kit used for analysis of different adulterants in milk samples such as urea, starch, neutralizers, detergent, sugar, mastitis, hydrogenperoxide, formaldehyde, maltodextrin, nitrate nitrogen, glucose, acidity and heat stability, sodium chloride.

\section{Detection of starch}

Reagent: Starch reagent (ST-1)

Addition of starch increases the SNF content of milk. Wheat flour, arrowroot, rice flour, etc., can also be added for increasing the SNF content. $3 \mathrm{ml}$ milk was taken in a test tube and boiled thoroughly. The milk was cooled to room temperature. 2 to 3 drops of (ST-1) was added. Change of colour to blue indicates that the milk is adulterated with starch.

\section{Detection of glucose}

Reagent: Glucose reagent-1 (G-1), Glucose reagent-2 (G-2)

Poor quality glucose is sometimes added to milk to increase the lactometer reading.

One $\mathrm{ml}$ of milk in a test tube was taken and 1 $\mathrm{ml}$ (G-1) was added and mixed thoroughly. The test tube in a boiling water bath was kept for $3 \mathrm{~min}$ and then cooled for $2 \mathrm{~min}$ by immersing it in tap water without disturbance. $1 \mathrm{ml}$ of (G-2) was added and shacked. When the change of colour to blue is visible, then presence of glucose in the milk sample is confirmed.

\section{Detection of urea}

Reagent: urea reagent (UR-1)

Urea is generally added in the preparation of synthetic milk to raise the SNF value.

$2 \mathrm{ml}$ of milk sample in a test tube with addition of $2 \mathrm{ml}$ of (UR-1) turns distinct yellow in colour, then the given sample of milk having urea become confirmed.

Control, normal milk may show a faint yellow colour due to presence of natural urea.

\section{Detection of salt}

Reagent: sodium chloride (SC-1), sodium chloride (SC-2),

Addition of salt in milk is mainly resorted to with the aim of increasing the corrected lactometer reading. $2 \mathrm{ml}$ of milk sample in a test tube was added with 2 to 3 drops of (SC$1)$.

$1 \mathrm{ml}$ of (SC-2) was added to milk. If the contents of the test tube turn yellow in colour indicates the salt.

\section{Detection of detergents in milk}

Reagent: Detergent reagent (DT-1)

$5 \mathrm{ml}$ of milk in test tube was added with $5 \mathrm{ml}$ of (DT-1). Normal milk use a pale grey is purple color a dark color indicate the presence of detergents of (abnormal milk with increase alkalinity in a milk)

\section{Detection of neutralizers}

Reagent: Neutralizer reagent $-1(\mathrm{Nt}-1)$

$5 \mathrm{ml}$ milk sample in a test tube was taken; 4 drops of neutralizer reagent-1 was added and 
mixed. Red color or deep rose red color indicates the presence of neutralizers in milk.

\section{Detection of sugar}

Reagent 1. sugar reagent -1 (s-1), 2. sugar reagent-2 (s-2)

$5 \mathrm{ml}$ of milk samples in a test tube was taken; $2 \mathrm{ml}$ of sugar reagent-1 (s-1) and 4 drops of sugar reagent-2 (s-2) were added. The contents in tube were placed in boiling water both for $2 \mathrm{~min}$, a red color indicates the present of sugar in milk

\section{Detection of acidity and heat stability}

Reagent: acidity reagent (A-1)

$2 \mathrm{ml}$ of milk sample in a test tube was taken and $2 \mathrm{ml}$ of acidity reagent (a1) was added and mixed well. The color of the mixture and presence of any flakes or clots were noted. The present of flakes of clots indicate a positive result of acidity in milk. Milk showing positive result is not suitable and not considered for the manufacture of evaporated milk. The percentage of acidity with respect to size of the flask and color is approximately as follows

\section{Detection of hydrogen peroxide}

Reagent hydrogen peroxide reagent -1 (hp-1)

$5 \mathrm{ml}$ of milk sample in a test tube was added with $1 \mathrm{ml}$ of hydrogen peroxide reagent 1 and mixed well and kept for 5 min.

A distinct yellow color indicates the presence of hydrogen peroxide in milk.

\section{Detection of mastitis}

Reagent: mastitis reagent (m-1)

$5 \mathrm{ml}$ milk sample in a test tube was added with $1 \mathrm{ml}$ of mastitis reagent and mixed well.
Normal milk gives a yellow color. Milk from infected udders gives a green color

\section{Detection of formaldehyde}

Reagent: formaldehyde reagent (FR-1), formaldehyde reagent (FR-2)

$5 \mathrm{ml}$ of milk sample in a test tube was taken and 2 drop of formaldehyde reagent- 1 was added and mixed. Then $1 \mathrm{ml}$ of formaldehyde reagent-2 was added very slowly and carefully along the side of the test tube a violet color ring at the junction of the milk and reagent indicates the presence of formaldehyde in milk. Normal milk gives a light brown color ring at the junction.

\section{Detection of maltodextrin}

Reagent: maltodextrin reagent (MD-1), maltodextrin reagent (MD-2).

$10 \mathrm{ml}$ of milk in a test tube was added with $1 \mathrm{ml}$ of maltodextrin reagent 1 and boiled for few min., cooled and filtered. To a $5 \mathrm{ml}$ of filtrate, 2-3 drop of maltodextrin reagent 2 was added and mixed well. A brown color indicates the presence of maltodextrin in milk and normal milk gives a golden yellow color.

\section{Detection of nitrate nitrogen}

Reagent: nitrate nitrogen reagent $1(\mathrm{NN} 1)$

$2 \mathrm{ml}$ of milk in a test tube was added with 0.5 $\mathrm{ml}$ of nitrate nitrogen reagent 1 along the side of the test tube, a blue color indicate the presence of nitrate nitrogen in milk.

\section{Results and Discussion}

\section{Adulteration with neutralizer}

The data belonging to extent of adulteration in milk samples is given in Table 1 and the findings regarding neutralizer are presented in 
Figure 3. Neutralizers are generally used to mask the $\mathrm{pH}$ and acidity values of badly preserved milk passing it off as fresh milk (Faraz et al., 2013). As per the results, 12\% and $20 \%$ of samples collected from MV and $\mathrm{RS}$ respectively were positive for neutralizers and 23 samples were negative results for neutralizers. Similar results were obtained by Chintha siva Swetha et al., (2014), Ramya et al., (2015) and Singuliri and Sukumaran (2014). According to (Rideout et al., 2008) presence of neutralizers may cause disruption of hormones which are important for development and reproduction.

\section{Adulteration with sodium chloride}

The data belonging to extent of adulteration in milk samples is given in Table 1 and the findings regarding neutralizer are presented in Figure 4. Sodium chloride was added in milk to mask the higher water content. Out of 30 unpasteurized milk samples, 30\% samples were found to be positive for sodium chloride. Similar results were observed by Chinta Siva Swetha et al., (2014), Ramya et al., (2015) Singuluri and Sukumaran (2014). High level of sodium chloride in milk could affect the acid base balance in body and may develop regression loss of acquired immunity, kidney problems, speech and sensory disturbances reported by Ayub et al., (2007).

\section{Adulteration with acidity}

The data belonging to extent of adulteration in milk samples is given in Table 1 and the findings regarding neutralizer are presented in Figure 5. Acidity and heat stability was added to correct the $\mathrm{pH}$ of milk. As per the results, $37 \%$ samples show the positive results for acidity. Similar results were observed by Indumathi and Obula Reddy (2015).

\section{Adulteration with mastitis}

The data belonging to extent of adulteration in milk samples is given in Table 1 and the findings regarding neutralizer are presented in Figure 2. Out of 30 samples $43 \%$ of samples showed positive results. Similar results were observed by Shrishti Nirwal, Rakesh Pant and Nishant Rai.

Fig.1

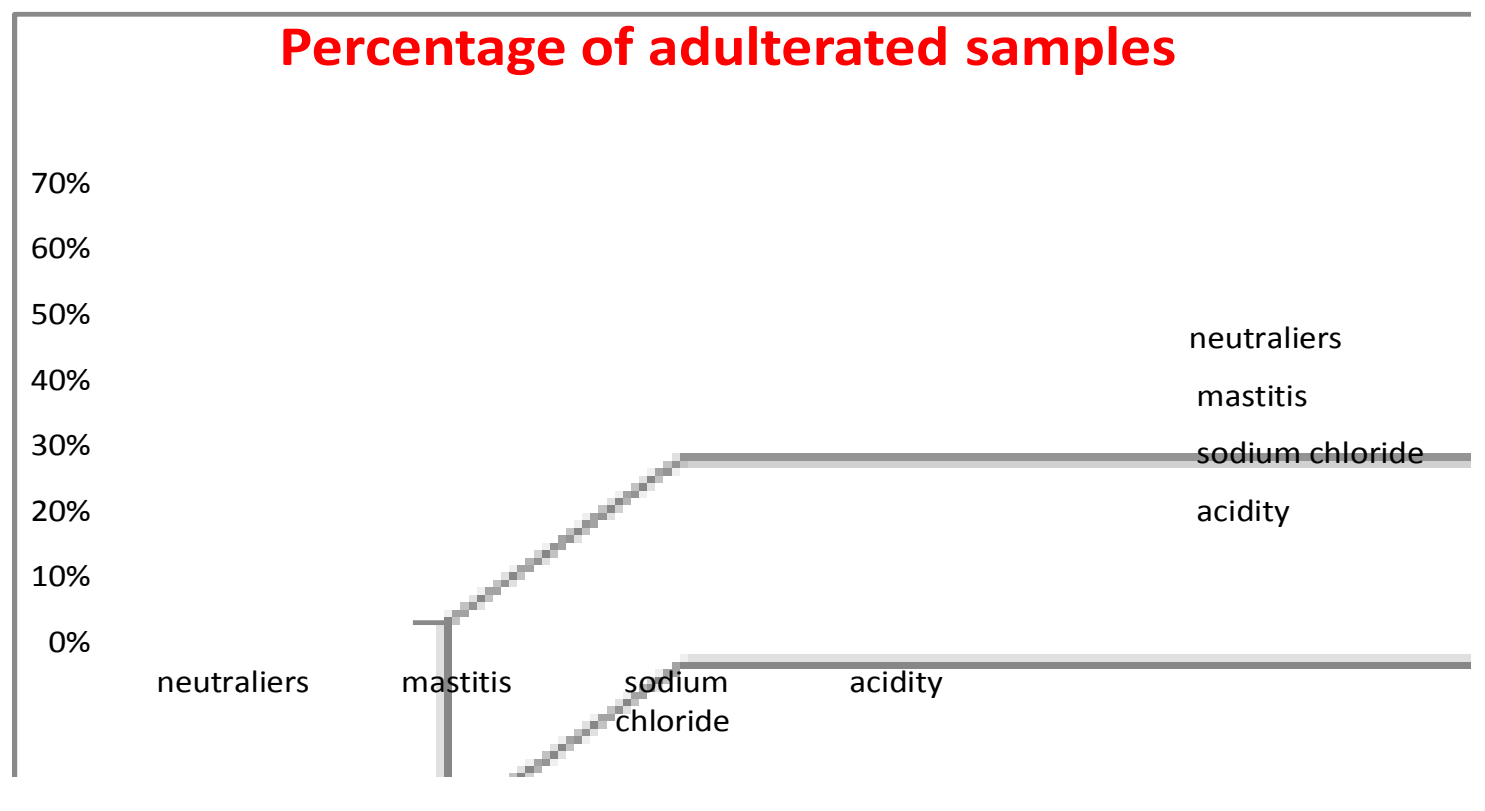


Fig.2

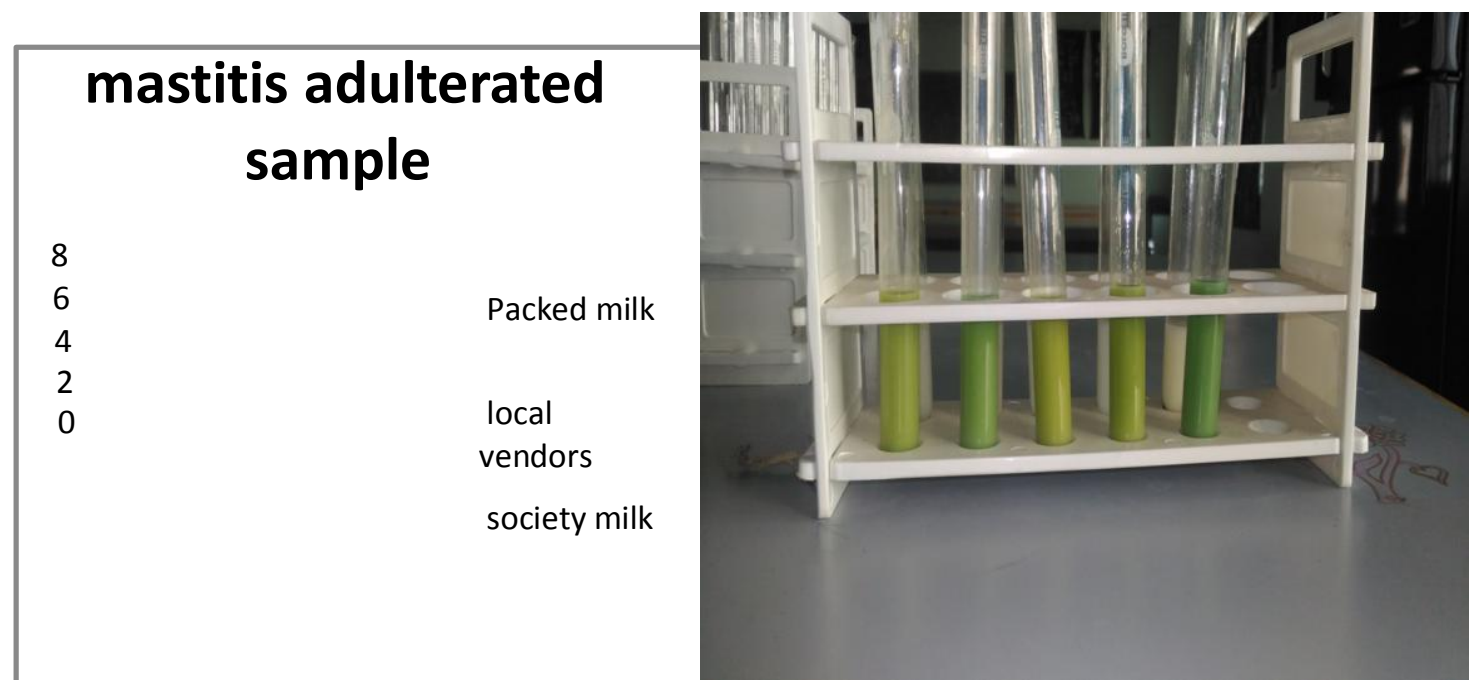

Fig.3

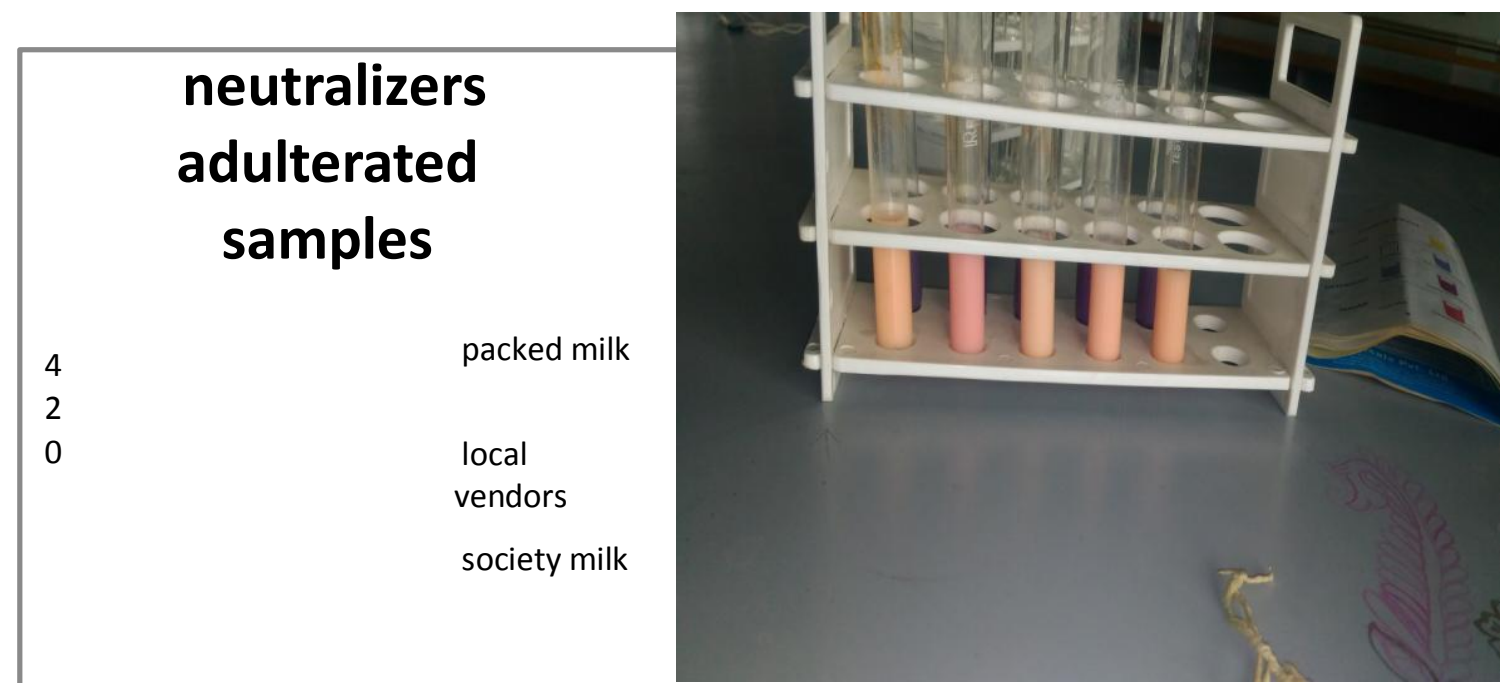

Detection of acidity and heat stability

\begin{tabular}{|l|l|l|}
\hline Color & Size of the flasks & Acidity (as lactic acid) \\
\hline Lilac & - & Up to $0.14 \%$ \\
\hline Pale red & - & 0.14 to $0.17 \%$ \\
\hline Reddish brown to brown & Small flasks & 0.17 to $0.20 \%$ \\
\hline Brownish yellow to yellow & Large flasks & Above $0.20 \%$ \\
\hline
\end{tabular}


Fig.4

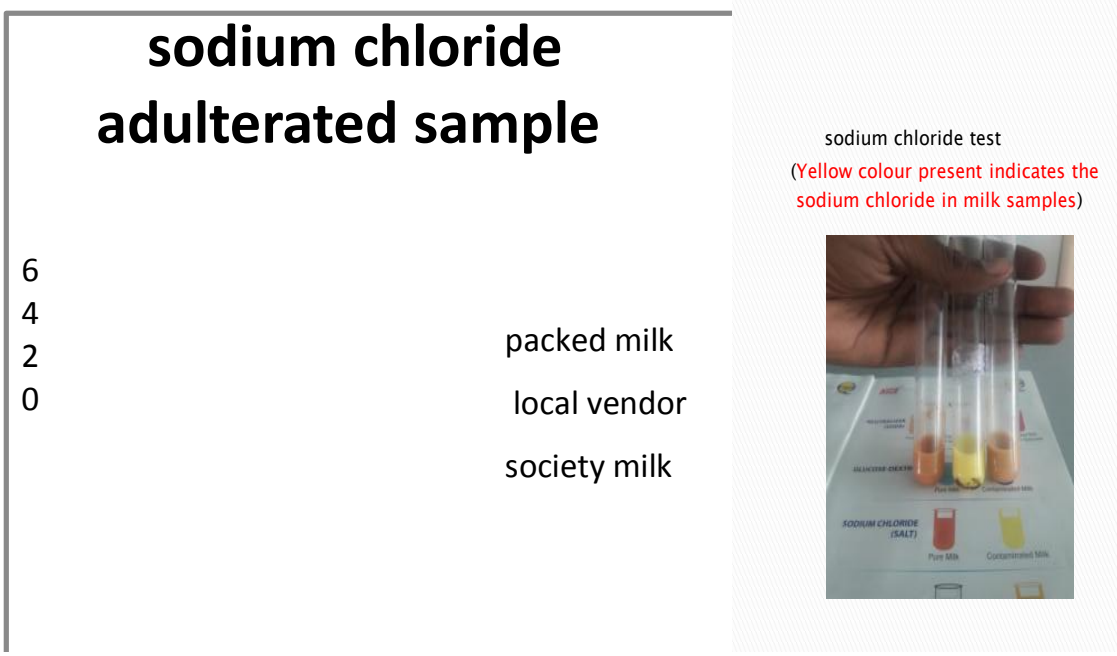

Acidity and heat stability test

(color of the mixture \&presence of flakes indicate the acidity)

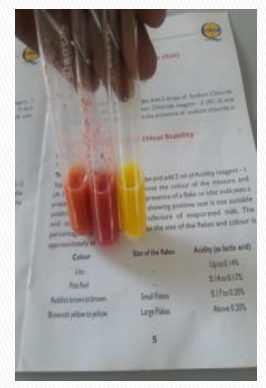

Fig.5

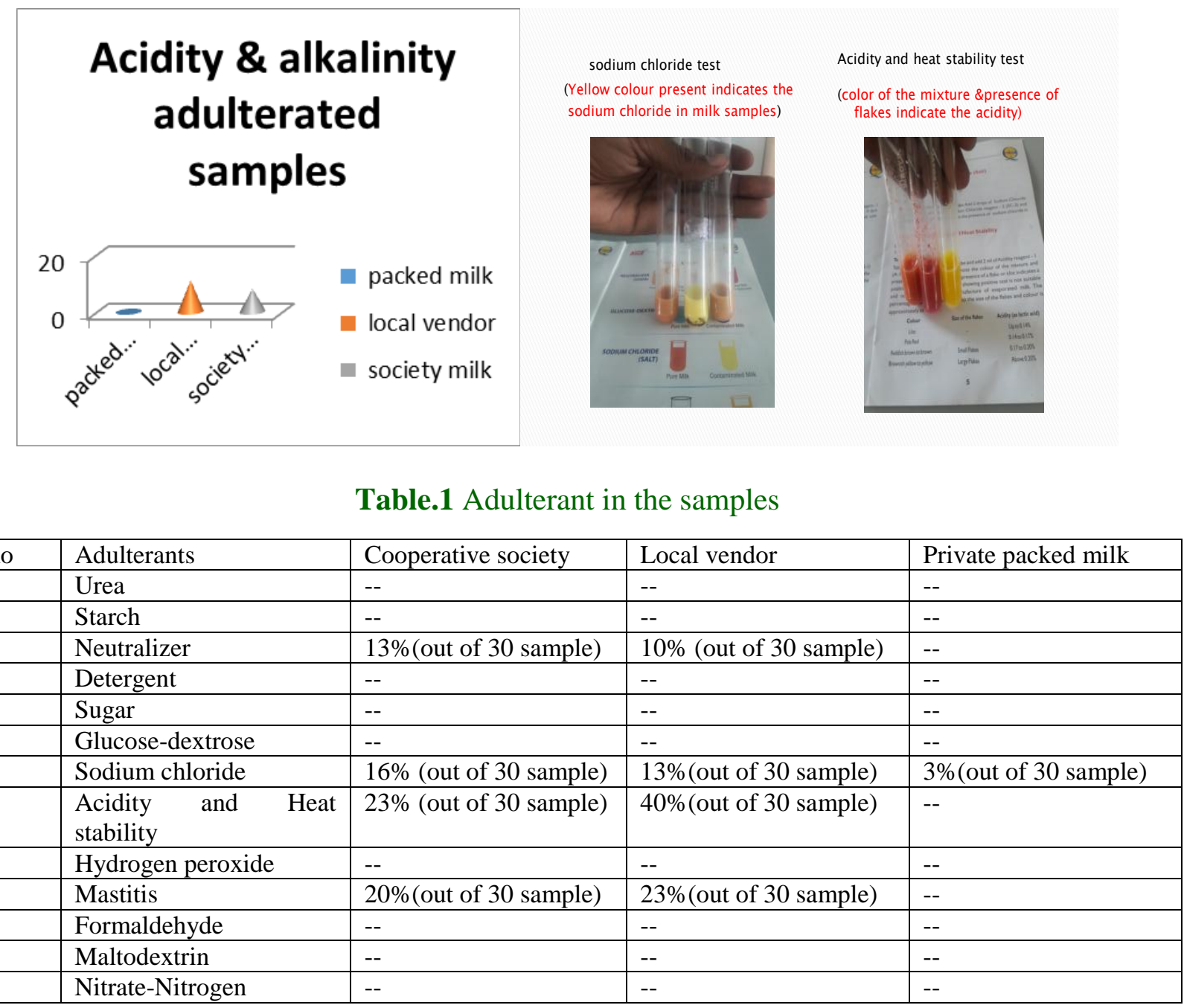


After surveying and testing the milk samples, the results were quite shocking. People only expected water to be present as an adulterant in their consumed milk but for some cases tests indicated the presence of other adulterants that are harmful for health. Therefore this contradictory information shows that consumers are unaware of these adulteration practices. So spreading the awareness among the people about different types of adulterants that can be present in milk and harmful effects on their health can be an appropriate recommendation in this case.

From the vocal opinion of the consumers gathered, administration is very lenient in this case. So the government should periodically collect samples and do tests to make sure the quality of the milk supplied and consumed by the people.

A technical approach towards this problem can be a small portable and economical milk test kit. The kit should have simple tests that the consumers can do to check the quality of their milk. The kit should be affordable and easily available in the market and should be subsidized by the government. It should have a lactometer for testing the percentage of water in milk and few other chemical for other basic tests like powder milk, detergent, and urea. With such a method, consumers can check the quality of milk before buying them from vendors. Vendors selling adulterated milk should be interrogated and his practices should be banned.

\section{References}

Ayub, M., Ahmed, Q., Abbas, M., Qazi, I.M. and Hattak, I.A. 2007. Composition and adulteration analysis of milk samples. Sarhad Journal of Agriculture. 23(4): 11271130.
Chinta Siva Swetha, Bharathy Sukumar and Sudhanthiramani Sudhanthirakodi 2014. The Study on Detection of Adulteration in Milk Samples Supplied by Local Vendors in Tirupathi Region, India- shanlax international Journal of veterinary science Vol.2 No. 2

Faraz, A., Lateef, M., Mustafa, M.I., Akhtar, P., Yaqoob, M. and Rehman, S. 2013. Detection of adulteration, chemical composition and hygienic status of milk supplied to various canteens of educational institutes and public places in Faisalabad. J. Animal Plant Sci. 23: 119-124.

FSSAI, 2011. Executive Summary on National Survey on Milk Adulteration.

http://dahd.nic.in/Division/statistics/animalhusbandry-statistics-division BAHS-2016.

Indumathi J and Obula Reddy B 2015. Quality evaluation of milk samples collected from different intermediaries at the vicinity of Chittoor district, Andhrapradesh, IndiaInternational Journal of Current Advanced Research 4(10): 436-40.

Nirwal, S., Pant, R. and Rai, N. (2013). Analysis of milk quality, adulteration and mastitis in milk samples collected from different regions of Dehradun. International Journal of Pharmtech Research.

Ramya, P., Swetha C.S., Venkateswara Rao, L., Tirupathi Reddy, E. and Jagadeeshbabu, A. 2015. Detection of adulterants in retail milk samples procured in proddatur town, YSR Kadapa (dt), Andhra Pradesh. Int. J. Agric.Sc \& Vet.Med. 3: 1.

Rideout, T.C., Liu, Q., Wood, P. and Fan, M.Z. 2008. Nutrient utilization and intestinal fermentation are differentially affected by the consumption of resistant starch varieties and conventional fibres in pigs. Br. J. Nutr. 99: 984-92.

Shrishti Nirwal, Rakesh Pant and Nishant Rai. 2013. Analysis of milk quality, adulteration and mastitis in milk samples collected from different regions of Dehradun. Int. J. of PharmTech Res. 5(2): 359-364.

\section{How to cite this article:}

Brindha, N., P. Chitra, R. Janarthanan and Murali, A. 2017. A Study on Detection of Adulteration in Milk Samples from Different Regions of Thuraiyur District in Tamil Nadu, India. Int.J.Curr.Microbiol.App.Sci. 6(12): 3303-3310. doi: https://doi.org/10.20546/ijcmas.2017.612.384 